\title{
Vladímir Nabókov: as artes da tradução
}

\author{
Graziela Schneider Urso*
}

\begin{abstract}
This paper will look at Vladimir Nabokov in the light of the interrelation between writing and (self-)translating, highlighting intersections of (re)reading, (re)translating, (re)creating, (re)editing, (self)translating and (re)writing. His being trilingual from an early age did not make Nabokov's path to changes and ultimate exile - from his Language - less complex than his farewell to and increasing distance from his Land, both being recollected and recreated through memory and otherness. Chameleonic writer, translator, teacher, scholar and theoretician, Nabokov takes hold of self-translation, intertwining the limits of Life, Art, Fiction, Metaphor, and transforming self-translation transpositions into an "eternal return", infinite process of re-writing and re-creating the (de)construction of the new literary text in the new language, in a fusion of past and future. Challenging the boundaries of Literature, Language, and Translation through prose-poetry, traditional-modern, conservativeinnovative, originals-translations dichotomies, Nabokov orchestrates the art of composition and intertextuality - culminating in the unique Nabokovian poetics punning with the omniscient, omnipresent, and omnipotent consciousness of writing and translating and the incompleteness of expression and speech before thought and feeling. The frantic experience of translating for the first time from Russian into Portuguese Nabokov's "Spring in Fialta" (1956), in parallel to the Russian text's confrontation with the author's self-translation into English and his translation processes, raises issues about the dislocations in his literary landscape and language, and observe the relation between (re)reading, (re)writing, (self)translating and plural cultural and artistic identities, revisiting the Nabokov writer as a translator and the Nabokov translator as a writer.
\end{abstract}

Keywords: Nabokov, Vladímir 1899-1977 - Russian Literature - Russian Culture Russian - Translation - Self-Translation.

\footnotetext{
" Doutoranda do Programa de Pós-Graduação em Literatura e Cultura Russa, do DLO, FFLCH, USP; tradutora. Email: graziela_schneider@yahoo.com.br.
} 
Resumo: 0 presente artigo considerará Vladímir Nabókov ${ }^{\dagger}$ à luz da interrelação de escrever e (auto)traduzir, realçando as intersecções de (re)ler, (re)traduzir, (re)criar, revisar, (auto)traduzir e (re)escrever. Ser trilíngue desde a infância não tornou sua trajetória de transformações e o derradeiro exílio - de sua Língua - menos complexos do que a partida e a crescente distância - de sua Terra - ambas, rememoradas e recriadas pela memória, continuam em sua ficção. Escritor, tradutor, professor, teórico camaleônico, Nabókov se apodera da autotradução, entrelaçando os limites da Vida, Arte, Ficção, Metáfora, transformando transposições de autotradução em um eterno retorno de infinitos processos de (re)escritura e (re)criação da (des)construção do novo texto literário na nova língua, em uma fusão de passado e futuro. Desafiando as fronteiras entre Literatura, Linguagem e Tradução em dicotomias poético-prosaicas, tradicional-modernas, e caminhos entre originais e novos originais, Nabókov orquestra a arte da composição e a intertextualidade, culminando em uma poética nabokoviana sui generis - uma consciência onisciente, onipresente e onipotente da escritura e do ato tradutório e da incompletude da expressão diante do pensamento e sentimento. 0 enlevo de traduzir pela primeira vez, do russo ao português, contos da coletânea Primavera em Fialta (1956), que o próprio Nabókov reuniu, em paralelo ao cotejo com as autotraduções desses contos para o inglês e seus processos de tradução, suscita questões sobre os deslocamentos em sua paisagem e língua literária e sobre a relação entre (re)ler, (re)escrever, (auto)traduzir e identidades culturais e artísticas plurais, revisitando o Nabókov escritor como tradutor e o Nabókov tradutor como escritor.

Palavras-chave: Nabókov, Vladímir 1899-1977 - Literatura Russa - Cultura Russa Língua Russa - Tradução - Autotradução.

\footnotetext{
${ }^{\dagger}$ A grafia do sobrenome do escritor em português levará acento, salvo em casos de citações em que outros tradutores tenham utilizado grafia diferente ou em referências de obras em inglês.
} 
Schneider, Graziela - Vladímir Nabókov: as artes da tradução

\section{Prólogo}

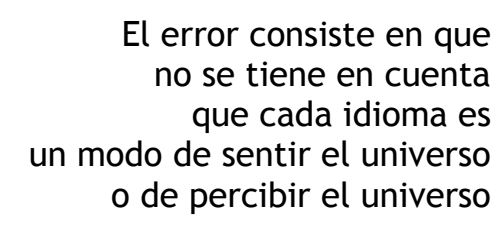

J. L. Borges

A presente Comunicação é uma colagem da Dissertação “A Face Russa de Nabókov: Poética e Tradução", com orientação da Profa. Dra. Elena Vássina, que se inseriu no Programa de Pós-Graduação em Literatura e Cultura Russa, do Departamento de letras Orientais da FFLCH, USP.

A partir de leitura do texto "The Art of Translation" (NABOKOV 1981: 315-321), surge a ideia da confluência entre os processos de leitura, tradução, escritura, autotradução e recriação, idioma criador e identidades culturais e artísticas. O poema de Dante Moreira Leite, Ofício, condensa essa ideia:

\section{Ofício}

Ver. Rever. Desver.

Rever o visto, desrever.

E novamente rever.

Longe, o tradutor

Mais longe ainda, um autor

Depois, o revisor

E o linotipista

E o revisor do revisor.

Serão palimpsestos?

Serão alfarrábios, escritas cuneiformes,

Hieróglifos - ou apenas glifos?

Grifos ou negritos?

Itálico ou redondo?

Tipo 33 ou 36?

0 revisor vê. Revê.

Tudo visto e revisto

Ainda relê

E finalmente deslê.

(Dante Moreira Leite) 


\title{
1 Introdução: Criação como Vida
}

\author{
"E teço versos como quem refaz \\ a vida." \\ Odylo Costa, filho
}

Tudo em Nabókov é re-torno - re-ler, re-visar, re-criar. A reiteração dá a ideia de seu incessante trabalho de construção e re-elaboração poética, que intensifica e aprofunda a relação entre o receptor e o objeto artístico. "Nabókov não apenas escreve de uma maneira nova, aprendemos com ele a também ler de um jeito novo" (BERBÉROVA 1970: 228):

uma pessoa não pode ler um livro: ela só pode relê-lo. Um bom leitor, um leitor primordial, um leitor ativo e criativo é um re-leitor. [...] Quando lemos um livro pela primeira vez o próprio processo laborioso de mover nossos olhos da esquerda para a direita, linha após linha, página após página, esse complicado trabalho físico sobre o livro, o próprio processo de descobrir o que é livro em termos de espaço e tempo, ficam entre nós e a apreciação artística. [...] Não temos um órgão físico (como temos o olho para um quadro) que assimile a imagem toda e então pode apreciar seus detalhes. Mas em uma segunda, terceira, quarta leitura nos comportamos diante de um livro, até certo ponto, como nos comportamos diante de um quadro. (NABOKOV 1980: 03. Negrito meu).

A busca por um "equilíbrio artístico harmonioso entre a mente do leitor e a do autor", em um processo que conta com "imaginação impessoal e deleite artístico" do leitor, (NABOKov 1980: 04) faz da arte da composição nabokoviana, intertextual e metamórfica, um percurso entre tradição e inovação, permeado de diálogos culturais multiliíngues e jogos labirínticos de palavras e enredos.

Vladímir Vladímirovitch Nabókov passa a vida se metamorfoseando. Nasce em São Petersburgo em 23 de abril de 1899, onde teve uma infância idílica e sólida formação cultural, como "uma perfeita criança trilíngue em uma família com uma ampla biblioteca” (NABOKOV 1990: 43, grifo meu), que 
depois "exemplifica as privações culturais da emigração sobrevivente" (VoLKov 1997: 330).

Em uma típica família aristocrática, "VN aprendeu primeiro inglês e depois francês com várias governantas; seu pai, quando percebeu que o filho lia e escrevia em inglês, mas não em russo, contratou um instrutor de uma escola local para ensinar VN e seu irmão Serguei sua língua nativa. A família Nabókov costumava falar em casa uma mescla de francês, inglês e russo, e essa diversidade linguística desempenharia um papel primordial no desenvolvimento de VN como artista." (HAMILTON. Negrito meu).

A exposição a esse opulento ambiente cultural e linguístico e a sua "biblioteca universal" particular culminaria em uma trajetória artística múltipla e um estilo nabokoviano entretecido.

Quando da Revolução Russa, os Nabókov foram obrigados a deixar São Petersburgo, partindo primeiro para a Crimeia, e logo emigrando para a Europa Ocidental, em condições precárias, para nunca mais voltar.

É o início de uma sucessão de episódios trágicos: a forçosa partida, os percalços, o assassinato do pai (quando este tenta impedir o assassinato de um político por monarquistas de direita), novas adversidades, novas partidas inevitáveis e novos re-começos, a morte do irmão Serguei em um campo de concentração, os anonimatos, os favores dos amigos e conhecidos, a eterna vida itinerária.

Entretanto sua Terra e sua Língua continuam em sua ficção. 0 constante estado de impermanência, "neither here nor there" leva a intermitentes processos de re-negociação de identidade, culminando em um estilo, linguagem e escritura nabokoviano muito sui generis: nem russo, nem inglês, nem francês, mas seu russo, seu inglês, seu francês (con)fundindo-se em uma linguagem entremeada, híbrida, "deslocante”, movediça.

Esse caráter irrevocável e inexorável das circunstâncias e das transformações que experiencia molda suas traduções de si mesmo: suas criações e re-criações. 
Nabókov estuda letras (francês e russo) na Universidade de Cambridge. Depois do brutal assassinato do pai, em 1922, muda-se para Berlim, onde vive até 1937, exercendo inúmeras atividades para sobreviver com dificuldades, sobrando-lhe menos tempo do que gostaria para escrever.

Em 1925, casa-se com Véra Slónim, eterna companheira. Em 1934, nasce seu único filho, Dmítri Vladímirovitch Nabókov, que depois se tornaria seu fiel tradutor.

A primeira metade de sua vida literária ele escreve quase que exclusivamente em russo. Ainda na Rússia, desde muito cedo, começara a escrever poesia e, nos anos berlinenses, consolida-se, como Vladímir Sírin, um dos escritores mais reconhecidos da literatura russa da emigração, publicando vasta obra prosaica, dramática e poética, destacando-se como

\footnotetext{
"Um tremendo escritor, maduro, sofisticado, moderno [...]; um grande escritor russo, como um fênix, [que] nascera do fogo e das cinzas da revolução e do exílio. A partir de então, nossa existência tinha adquirido significado. Toda minha geração estava justificada. Estávamos salvos." (BERBEROVA 1970: 225).
}

A recepção da obra nabokoviana russa nos círculos de emigrantes mostrava que "algo grande, distinto, algo original, prodigioso em escala mundial, podia emergir entre os Akáki Akákievitchs ${ }^{1}$ da Europa" (idem 1970: 226, e que "na perspectiva do passado e do futuro, Nabókov é a resposta a todas as dúvidas dos exilados, dos perseguidos, ofendidos e prejudicados, os “despercebidos” e os “perdidos”!" (idem 1970: 227).

Berbérova condensa:

\begin{abstract}
“Estou nas 'encruzilhadas poeirentas' e olho para sua 'procissão real' com gratidão e com a consciência de que minha geração (inclusive eu, claro!) viverá nele, de que ela não desapareceu, não se dissolveu entre o cemitério Billancourt, Xangai, Nova York e Praga. Todos nós, com todo nosso peso, sejamos bem-sucedidos (se é que os há) ou mal-
\end{abstract}

\footnotetext{
1 Personagem de 0 Capote, de Nikolai Gógol. Cf. o texto de ElKhenbaum, "Como é feito o Capote de Gogol”. In: Teoria da Literatura - Formalistas Russos. Porto Alegre: Globo, 1973, pp. 227-244.
} 
Schneider, Graziela - Vladímir Nabókov: as artes da tradução

sucedidos nos apoiamos nele. Se Nabókov está vivo, significa que eu também estou!" (ibidem 1970: 226).

O dever estético de pertencer à " elite cultural émigré"”, que “"não era exilada, mas emissária', responsável pela preservação da herança russa, sob ataques dos novos donos do país", de portar "a influência da mensagem cultural" emigré, "endereçada ao público ocidental moderno tanto quanto às futuras platéias da Rússia 'pós-comunista'” (Volkov 1997: 339-340) era também moral. Sua língua, cultura e história eram resgatadas, recriadas e resguardadas em seu Texto.

[N]a arte da literatura ... a língua é a única realidade que divide essa arte universal em artes nacionais. (NABOKOV 1981: 323, grifo meu). Quando a Rússia "reaviu" a inestimável herança nabokoviana,

[u]ma animada polêmica desenvolveu-se em torno da obra de Nabokov, que para muitos parecia preocupado demais com a "estética" e condescendente. Respondendo a tais acusações, Andrei Bitov afirmou que "não está claro o que predomina - orgulho e esnobismo, ou timidez e modéstia. [...] Não acredito que Nabokov pretendesse ensinar inglês ao idioma russo, mas de alguma forma ele conseguiu ensinar russo à língua inglesa, o que não é pouco”. (VolKov 1997: 533, grifo meu).

Depois de passarem alguns anos em Paris, devido à ascensão e iminentes ameaças do Nazismo, em 1940, o escritor, a mulher e o filho se mudam para os EUA. O novo exílio acarreta novas perdas e arduidades, a precisão de novo começo, país, idioma e identidades, e Nabókov "pondera as possibilidades de reformular radicalmente sua identidade de escritor" (ConNolLy 2005: 06, grifo meu).

Quando está prestes a re-emigrar, Nabókov inicia um processo de alteração da língua de criação, do russo para o inglês. É nesse momento que ele começa a se apoderar da autotradução, a princípio por uma profunda insatisfação com a tradução de "Камера обскура" (1932) [Kámera obskúra/Riso no Escuro], depois de inúmeras e insistentes exigências de "uma tradução exata, completa e correta”: "o que é mais difícil em relação a um 
Schneider, Graziela - Vladímir Nabókov: as artes da tradução

autor que busca a precisão absoluta no seu trabalho, faz os maiores esforços para alcançá-la, e então vê o tradutor desfazer calmamente cada frase sagrada" (NABOKov 1989: 13, grifo meu), como se estivesse "testemunhando um assassinato e não pudesse fazer nada para impedi-lo" (NABOKOV 1981: 318).

Os deslocamentos físicos e a mudança da língua de criação de russo para inglês compõem identidades culturais e artísticas complexas - Nabókov escreveu em russo e inglês, mas, de forma bem marcada: depois de produzir vasta e expressiva obra em língua russa passa a escrever quase que exclusivamente em inglês.

Há uma cisão quando deixa de criar em russo e passa a criar em inglês, e recriar em russo, mas continua a escrever poesia em russo e a (auto)traduzir para esse idioma: a poesia e a (auto)tradução são sua conexão artísticoliterária com a língua russa.

A mutação de russo para inglês e do alter ego Sírin para Nabókov simboliza uma tradução de si mesmo, uma transferência um tanto quanto consciente, e a transformação da língua de criação apresenta-se como cisão e projeto artístico-literário. Depois de duas rupturas, primeiro quando deixa a Rússia, e depois a Europa Ocidental, paira a ideia de mutilação e escolha:

\footnotetext{
"[...] olhando para a beleza perdida e a imensa opulência de sua infância, pode-se com razão esperar um sentimento de tristeza, senão de amargura. É lugar-comum na crítica de Nabokov que essa perda prematura energizou seu gênio e modelou sua mais poderosa ferramenta, a memória [...]"; "ele não apenas tinha sobrevivido a essa perda esmagadora, ele tinha continuado a florescer" [...]. "Ainda mais difícil de avaliar é a dificuldade do que ele fez em seguida [...]: trocar de idioma após ter desenvolvido um novo e brilhante estilo em russo." (PROFFER 1994: 05, grifo meu)
}

Segundo ConNolly "Quando o próprio Nabókov contemplava as mudanças sísmicas que ele experienciou, tendia a vê-las não como aleatórias, díspares, ou deslocadas [...] [mas] preferia enxergar sua vida de forma estética. [...] uma das imagens mais importantes e recorrentes em sua ficção é a noção da vida como 'texto.'” (ConNolly 2005: 02, grifo meu). 
Schneider, Graziela - Vladímir Nabókov: as artes da tradução

Em muitas cosmogonias, a criação é filha da palavra. A "literatura pertence não ao departmento das ideias gerais, mas ao departamento das palavras e imagens específicas” (NABOKOV 1981: 323): “[o]s anjos, explicou-nos Nabókov, - são grandes e fortes. Capazes de matar com a asa. A palavra - é o "bater das asas'”." (Nabokov, apud Paramanov, 2000).

Somente depois da publicação de Lolita (1955), que se tornara um êxito, re-torna à Europa, onde permanece para o resto de sua vida, vivendo em um hotel em Montreaux, podendo finalmente dedicar todo o seu tempo a escrever, traduzir e/ou acompanhar a tradução de suas obras, realizar revisões ou recriações de seus textos, além de ocupar-se da lepidopterologia, sua outra paixão, "como se as convulsões da história nada tivessem alterado." (Boyd 1990: 03). Falece em Lausanne em 2 de julho de 1977.

\section{Tradução e cotejo}

A tradução direta do russo de contos inéditos da coletânea Primavera em Fialta (1956) e o cotejo com a versão em inglês realçam a face russa de Nabókov, ou seja, não apenas que nasceu e cresceu na Rússia, consagrou-se primeiro como autor russo e escreveu por mais de 20 anos nesse idioma, mas também que essa face continuou manifesta em toda sua obra. Os leitores brasileiros costumam não saber que muitos dos livros que leem do referido autor, traduzidos para o português do inglês, foram concebidos em russo e vertidos para o inglês, em geral pelo próprio autor ou por seu filho, Dmítri, "fruto de uma desanuviada colaboração entre pai e filho" (NABOKOV 1997: XV).

A tradução dos contos foi direta, do russo para o português; porém, entendendo os textos em inglês como diálogos com Nabókov, já que foram vertidos pelo próprio autor, ou por seu filho, mas supervisionados por ele, optou-se por um caminho mais complexo: traduzir do russo, realizando-se

\footnotetext{
${ }^{2}$ Do conto de Nabókov Удар крыла [Udár krilá], O bater das asas (1924).
} 
concomitantemente um cotejo elucidativo entre os contos em russo e a versão inglesa. E o que a princípio facilitaria o trabalho transforma-se em um processo labiríntico: esse diálogo não é nada óbvio, mas plural, vasto.

Aprofundando questões tradutológicas tanto da tradução dos contos do russo para o português como das artes da tradução nabokovianas, corroborando a compreensão e interpretação do texto russo, apontando elementos representativos, realçando o caráter e grau das mudanças do russo para o inglês, esse cotejo elucidativo-ilustrativo traz à tona outro viés: destacam-se as discrepâncias entre a versão russa e a inglesa, demonstrando a especificidade da tradução do russo, já que se trata de dois textos.

Assim, é possível perceber nitidamente como o texto inglês se distancia do texto russo. Foram constatadas diferenças leves: sutilezas, nuances, em geral por se tratar de duas línguas; diferenças consideráveis: adaptações, termos bem diferentes; diferenças totais ou inexistências: omissões e adições, palavras ou trechos completamente novos, termos ou passagens sumariamente descartados, mais, ou menos "justificáveis". Trata-se de parágrafos inteiros adicionados ou excluídos, mudanças gritantes que suscitam questionamentos, sem, contudo, entrar no mérito de juízos de valor.

Além disso, observam-se palavras ou trechos significativos; soluções interessantes que auxiliaram na tradução para o português, algumas das quais extremamente elucidativas, ou opções ideais para trechos ambíguos e passagens mais complexas, que apontam momentos expressivos e representativos da temática, ambiência e léxico nabokovianos. 


\section{2 (Auto)tradução como (re)criação}

Traduzir-se é uma tarefa assustadora, [...] olhar para as próprias entranhas e prová-las como se prova uma luva, e descobrir que o melhor dicionário não é um amigo, mas o campo inimigo.

NABOKOV

\section{Modus Vertendi nabokoviano}

Além da linguagem, estilo e temática nabokovianas, também a partir da tradução e do cotejo, por um lado, e de reflexões sobre o escrever e o autotraduzir ou reescrever nabokovianos, por outro, observam-se a teoria e a prática de tradução nabokoviana, o Nabókov autor e o Nabókov (auto)tradutor, e questiona-se até que ponto chega a autonomia do autotradutor, já que em princípio ninguém ousaria contestar essa autonomia, relativamente intocável e irrepreensível, visto que ele é o escritor e o tradutor, o criador e o re-criador.

Assim, distinguiram-se pelo menos três perspectivas possíveis quanto a um modus vertendi nabokoviano, de alguma maneira concorrentes, elencadas aqui não necessariamente em ordem crescente de importância, mas (crono)lógica - seguindo associações entre cada "papel”, que não estão nitidamente definidos, mas se (con)fundem uns nos outros em um processo entrelaçado por intersecções, interações e inter-relações: o Nabókov tradutor do outro; o Nabókov leitor, escritor, crítico e teórico de tradução; e o Nabókov tradutor de si mesmo, ou seja, autotradutor. 


\title{
Autonomia e desconstrução
}

\author{
Em seu "The Art of Translation" (NABOKOV 1981: 315-321), a princípio \\ parece partir de uma visão mais "clássica", "tradicional"/ "fechada" de \\ tradução, mas, separarando-se o tradutor do autotradutor tem-se uma visão \\ mais abrangente e inovadora:
}

\begin{abstract}
Podem-se distinguir três espécies de mal no estranho mundo da transmigração verbal. 0 primeiro, menor, compreende erros óbvios devido à ignorância ou conhecimento desorientado. Não passa de fraqueza humana, e, portanto, perdoável. 0 próximo passo em direção ao Inferno é tomado pelo tradutor que intencionalmente pula palavras ou passagens que ele não se dá ao trabalho de entender ou que possam parecer obscuras para leitores de imaginação vaga; ele aceita o olhar vazio que o dicionário the dá sem qualquer inquietação; ou sujeita erudição à afetação: ele está tão inclinado a saber menos do que o autor quanto a achar que sabe mais. Chega-se ao terceiro e pior grau de infâmia quando se faz um molde raso e rude de uma obra-prima, embelezada de maneira vil, de modo a se conformar às noções e preconceitos de determinado público. [...](NABOKOV 1981: 315, grifo meu)
\end{abstract}

[...]Podemos deduzir agora os requisitos que um tradutor deve possuir para ser capaz de dar uma versão ideal de uma obra-prima estrangeira. Em primeiro lugar ele deve ter o mesmo tanto de talento, ou pelo menos o mesmo tipo de talento, que o autor que ele escolhe. A esse respeito, e embora somente a esse respeito, Baudelaire e Poe ou Jukóvski e Schiller eram colegas ideais. Segundo, ele deve conhecer profundamente as duas nações e as duas línguas em questão e estar bem informado sobre todos os detalhes relacionados aos procedimentos e métodos de seu autor; além disso, à bagagem social das palavras, suas características, associações históricas e da época. Isso leva ao terceiro ponto: ao mesmo tempo que tenha gênio e conhecimento, ele deve possuir o dom da mimese e ser capaz de representar o papel do autor, encarnando suas artimanhas de procedimentos e discurso, seu jeito e sua mente, com o grau máximo de verossimilhança.(NABOKOV 1981: 319, grifo meu)

É importante notar que ele fala de verossimilhança e mimese e não equivalência ou fidelidade, literalidade.

Em geral Nabókov é considerado, por críticos e estudiosos de tradução, "clássico" e "tradicional” no que diz respeito a suas visões sobre tradução, 
Schneider, Graziela - Vladímir Nabókov: as artes da tradução

fidelidade, literalidade e erro, especialmente devido a sua tradução e comentário de "Evguêni Oniêguin", de Púchkin, e suas críticas mordazes sobre traduções alheias, sem se levar em conta a distinção entre o tradutor do Outro e o tradutor de si mesmo.

De fato ele defende o respeito ao autor, quando se trata de ele traduzir o Outro ou do Outro traduzi-lo; mas em "The Art of Translation", ele escarnece da literalidade:

Exceto embusteiros por excelência, imbecis inofensivos e poetas impotentes, há, grosso modo, três tipos de tradutores - e isso não tem nada a ver com minhas três categorias de mal; ou, melhor, qualquer um dos três pode errar de forma semelhante. Os três são: o estudioso que está ávido por fazer o mundo apreciar os trabalhos de um gênio obscuro tanto quando ele mesmo aprecia; o contratado bemintencionado; e o escritor profissional que quer relaxar na companhia de um colega estrangeiro. 0 estudioso será, espero, exato e pedante: notas de rodapé - na mesma página do texto e não enfiadas no final do volume - não poderiam ser mais copiosas e detalhadas. A senhora esforçada que traduz na décima primeira hora o décimo primeiro volume de alguma coletânea de trabalhos de alguém será, eu receio, menos exata e menos pedante; mas a questão não é que o estudioso cometa menos enganos do que um proletário; a questão é que, via de regra, tanto ele como ela são desesperadamente desprovidos de qualquer parentesco com o gênio criativo. Nem aprendizado, nem diligência podem substituir imaginação e estilo. (NABOKOV 1981: 319, grifo meu).

Entretanto, uma das especificidades do Nabókov autotradutor é justamente a de que em geral traduziu suas obras do momento russo - ou seja, quando ainda era Sírin - para inglês quando já começava a se tornar ou já tinha se tornado Nabókov, em um processo de deslocamentos físicos, lingüísticos e temporais, mudanças de paisagens, idiomas e momentos de criação.

Conforme aponta SCHEINER (2000), uma das facetas da autotradução em Nabókov é a total liberdade do escritor-tradutor, a autonomia das obras em russo e sua versão em inglês: a comparação entre a variante russa e a inglesa prova que são textos autônomos. Assim, a autotradução em Nabókov se dá com grande independência entre um texto e outro. 
Schneider, Graziela - Vladímir Nabókov: as artes da tradução

Guardadas as devidas proporções de originalidade e independência do texto traduzido, em algum momento o Nabókov inglês foi russo. Entretanto, embora prevaleça a ideia de "texto original" e sua "tradução", quando Nabókov se autotraduz ele é soberano, ninguém pode contestá-lo, os contornos entre esses conceitos, e entre escritor e tradutor ficam embaciados e depara-se com outro texto. Não há mais um original e uma tradução definidos, mas desconstruções, originais e traduções. É justamente nesse caso que ocorre a máxima realização: ele é duas vezes criador - como autor e como autotradutor.

Assim, as autotraduções nabokovianas apresentam fronteiras movediças e na prática não há original e tradução, mas originais e novos originais. Se o texto for considerado como um todo, quando se conta a história do russo ou a do inglês prevalece a mesma a mesma imagem semântica, a mesma impressão textual, as tramas são as mesmas; porém, quando se tem acesso ao texto russo e ao inglês, palavras, signos, em si, então os textos são linguisticamente diferentes, e as oposições um/o original $X$ uma/a tradução se desmancham para dar lugar a versões várias, revisões, recriações.

0 autor-tradutor, que está imerso nos dois lados da criação, tem uma posição, visão e percepção privilegiadas (TANQUEIRO 1999). Entretanto, da mesma forma que a proximidade favorece, desfoca, ofusca. Ele é o autor e o tradutor, não há como se separar de si mesmo.

O cotejo demonstra que em sua prática autotradutória Nabókov é ultramoderno: omite, acrescenta, desloca, compensa, e se vale de prólogos, prefácios e introduções para justificar sua liberdade total.

Dos demais tradutores exige "fidelidade", de si mesmo, onipresença, onisciência e onipotência. Se uma tradução deve refletir exatamente o que "o autor pensa", o que o criador "quis dizer", a "verdade" do autor (em contraposição com o que "o texto transmite", na interação autor-leitor), e a maneira em que o autor o formula em seus textos, e ele é o autor, é também o tradutor todo-poderoso. 
Schneider, Graziela - Vladímir Nabókov: as artes da tradução

Pablo de SANTIS (1999: 168) considera: "O trabalho do tradutor é feito de hesitações, assim como o trabalho do escritor. 0 escritor traduz-se a si mesmo como se fora outro, o tradutor escreve o outro como se fosse ele mesmo." Esse pensamento não serviria para o Nabókov tradutor:

\begin{abstract}
Agora vem o poeta autêntico, que possui os dois últimos bens e relaxa quando traduz um pouco de Liêrmontov ou Verlaine entre escrever seus próprios poemas. Ou ele não sabe a língua original e depende calmamente da denominada tradução "literal" feita para ele por uma pessoa de longe menos brilhante, mas mais cultivada, ou senão, sabendo a língua, ele não tem a precisão do estudioso e a experiência do tradutor profissional. Contudo, o principal ponto fraco, nesse caso, é o fato de que quanto maior for seu talento individual, mais apto ele vai estar a afogar a obra-prima estrangeira nas ondulações espumantes de seu próprio estilo pessoal. Ao invés de se vestir como o verdadeiro autor, ele veste o autor como ele mesmo. (NABOKOV 1981: 319, grifo meu).
\end{abstract}

Entretanto, poderia servir para o Nabókov autotradutor: se aquele que escreve traduz de seu pensamento ao papel, à palavra, à expressão, "aquele que traduz [...] se converte em parte de sua tradução [...]." (apud VermeER in GRBIĆ et WOLF 2007: 200). Nabókov é os dois. $O$ escritor é autotradutor e o autotradutor é escritor.

\title{
Autotradução e re-escritura
}

O Nabókov tradutor do Outro, que se aproxima do Nabókov leitor, estudioso, crítico, teórico de tradução e professor, é um (mais "tradicional", "clássico", apegando-se a noções de fidelidade); e o Nabókov tradutor de si mesmo, ou seja, autotradutor, que se aproxima do Nabókov escritor, autor, criador, e, portanto, da reescritura, é outro (mais "moderno", "inovador", "desconstrutivista").

Se para as traduções que os outros dilapidam e arruínam de seus textos ou de outrem, ele insiste na ideia de "erro", quando se trata de suas obras essas noções se (con)fundem, ele transgride o que defende. 
Schneider, Graziela - Vladímir Nabókov: as artes da tradução

Já as autotraduções nabokovianas são releituras, revisões, re-traduções que por sua vez são re-escrituras, em obsessivas relações entre leitura, escritura, deslocamentos, memória e tradução/re-escritura em meio a distâncias espaço-temporais.

Re-ler, re-ver e re-tocar são processos recorrentes em escritores, mas com o elã e afã nabokovianos isso se torna a própria força motriz da criação, (re)unindo leitura, tradução e escritura em um infinito re-tornar.

O seguinte trecho, do prólogo que Nabókov escreveu à última edição de "Speak, Memory" (NABOKOV 1999), um fragmento dos mais emblemáticos, senão o mais, da poética nabokoviana, ilustra a ideia da relação indissociável entre (auto)traduzir e (re)escrever:

No verão de 1953, em uma fazenda perto de Portal, Arizona, em uma casa alugada em Ashlan, Oregon, e em vários hotéis de beira de estrada no Oeste e Meio-Oeste, consegui, entre caçar borboletas e escrever "Lolita" e "Pnin", traduzir "Speak, Memory", com a ajuda de minha mulher, para o russo. Por causa da dificuldade psicológica de repetir um tema elaborado em meu "Dar" ("The Gift"), omiti um capítulo inteiro (11). Por outro lado, revi muitas passagens e procurei fazer algo com os defeitos amnésicos do original - lacunas, borrões, territórios obscuros. Descobri que, às vezes, com a ajuda de intensa concentração, a mancha neutra pode ser forçada a encontrar um belo foco para que a visão repentina possa ser identificada, e o servo anônimo nomeado. Para a presente edição final de "Speak, Memory" não apenas inseri mudanças básicas e adicionei copiosamente ao texto inicial inglês, mas me vali das correções que fiz quando o converti para - russo. Essa re-anglicização de uma re-versão russa do que inicialmente havia sido um re-contar inglês de memórias russas, provou ser uma tarefa diabólica, mas algum consolo me foi dado pelo pensamento de que uma metamorfose múltipla dessas, conhecida das borboletas, não havia sido experimentada por nenhum humano antes. ${ }^{3}$ (NABOKOV 1999: 05-06, tradução e grifo meus).

\footnotetext{
${ }^{3}$ Tradução da autora.
} 


\title{
3 Considerações finais
}

\begin{abstract}
A história retomada pela arte. Um truque com palavras: Nabokov escrevendo em inglês sobre um passado na Rússia em que todos falavam francês. 0 evento destilado em camadas de imagens, como um bourbon pelo carvão. ( $E$ a tradução em português estraga tudo.) A volta é sempre pela imaginação, nada é retomado inteiro. 0 que te acontece num minuto no minuto seguinte é história, no outro é invenção, no quarto é Nabokov. E aí não tem mais volta.
\end{abstract}

Luís Fernando Veríssimo

Observando-se o processo tradutório e (auto)tradutório de Nabókov suscitam-se questões atreladas às mudanças de paisagem e língua literária e percorre-se a interrelação entre escritura, tradução e identidade cultural e artística.

Multifacetado, também se destacou como tradutor e autotradutor, professor e crítico e teórico, e lepidopterologista, um verdadeiro scholar, o que pode ser comprovado por seus prefácios, suas lectures e os livros sobre literatura decorrentes delas, a tradução anotada de Evguêni Oniêguin, de Púchkin, as cartas. Para o russo traduziu Lewis Caroll, Romain Roland, e seu Lolita; para o inglês, Liêrmontov, Tiútchev, Púchkin, entre outros.

0 texto nabokoviano traz particularidades bem marcadas, evidências de um traçado distintivo sui generis, procedimentos estilísticos e linguísticos que descortinam como se opera em Nabókov a mescla de confluências, reverberações e heranças culturais, em especial a anglo-saxã, a francesa e a russa, devido a sua vivência, e como esse diálogo intertextual se faz presente na linguagem híbrida e inusitada: 
Schneider, Graziela - Vladímir Nabókov: as artes da tradução

Na Rússia, Nabokov parecia um pouco um inglês [...]. Na Inglaterra [...] seus amigos parecem ter sido, na maioria, russos, e em Berlim ele viveu uma existência inteiramente russa. Na América ele foi, naturalmente, um intelectual europeu. Finalmente, na Suíça, ele foi uma mistura de todas essas coisas - mas nunca suíço. Essa posição estranha à qualquer classificação parece ter-lhe caído bem [...]. Em relação a sua arte, a Rússia e a América parecem ter inspirado suas melhores obras, mas não há dúvida de que seu coração permaneceu com a Rússia - e os russos - de sua infância e juventude. (Proffer 1994: 05, grifo meu)

KELLMAN sugere que a autotradução parece representar também um projeto artístico vital: “No universo de Nabókov, no qual língua é identidade, a tradução é uma metáfora de metamorfose geral e eterna instabilidade. A imperfeição da transposição linguística é um lembrete das falhas em toda comunicação e da incomensurabilidade de Eu-mesmo e Outro" (KELLMAN 2000: 68, grifo meu).

Como indica Connolly (1992: 219, grifo meu): “Quando Nabókov começou a escrever em inglês, ele introduziu um tipo totalmente novo de 'outro' em sua ficção - a própria língua como meio". Embora escritores bilíngues não sejam incomuns, "bastante raro é um autor que se torna uma figura central em duas tradições linguísticas”. (KELLMAN 2000: 63, grifo meu), e pouquíssimos se lançaram no universo da autotradução, como Nabókov, Beckett e Kundera, cada um com suas especificidades.

O processo de alteração da escritura de russo para inglês e de Sírin para Nabókov, que se inicia um pouco antes da partida à América, está estreitamente entrelaçado aos procedimentos tradutórios nabokovianos: Nabókov se apodera da autotradução, desafiando as fronteiras entre Língua, Linguagem, Literatura e Tradução em dicotomias poético-prosaicas, tradicional-modernas, e caminhos entre originais e novos originais.

Despertando uma consciência onisciente, onipresente e onipotente do eterno retorno da escritura, do ato tradutório e da incompletude da expressão diante do pensamento e sentimento, Nabókov entrelaça os limites da Vida, Arte, Ficção, Metáfora e Tradução, transformando transposições de autotradução em infinitos processos de (re)escritura e (re)criação. 


\section{Referências bibliográficas}

Berbérova, N. Nabokov in the thirties. In: Appel JR., A.; Newman, C. (ed.). Nabokov criticism, reminiscences, translations and tributes, Evanston: Northwestern University Press, 1970.

BoYD, B. Vladimir Nabokov: The Russian years. Princeton: Princeton University Press, 1990.

Connolly, J. W. Nabokov's early fiction: patterns of self and other. Cambridge: Cambridge University Press, 1992.

- Introduction: The Many Faces of Vladimir Nabokov. In: The Cambridge companion to Nabokov. Cambridge: Cambridge University Press, 2005.

De SANTIS, P. La traducción. Barcelona: Destino, 1999.

EIKHENBAUM. Como é feito o Capote de Gogol. In: Teoria da Literatura Formalistas Russos. Porto Alegre: Globo, 1973.

Grbić, N. et Wolf, M. VermeER, H. J. A. skopos theory of translation (some arguments for and against). Heidelberg, TEXTconTEXT (Band 1). Resenha. TTR Traduction, terminologie, rédaction. V. 12, n. 2. Disponível em: <http://www.erudit.org/revue/ttr/1999/v12/n2/037383ar.pdf>. $(15 / 09 / 2007)$.

HAMILTON, J. Biography. Disponível em <http: / /www.libraries.psu.edu/nabokov/bio.htm>. (07/04/2009).

KELLMAN, S. G. The translingual imagination. Lincoln and London: University of Nebraska Press, 2000.

LEITE, D.M. O amor romântico e outros temas. São Paulo: Edusp: 1979.

NaвoKov, V. Lectures on literature. New York: Harvest, 1980. Edited by Fredson Bowers.

. Lectures on Russian literature. New York: Harvest, 1981. Edited by Fredson Bowers.

. Selected letters 1940-1977. San Diego: Harcourt, 1989. Edited by Dmitri Nabokov \& Matthew J. Bruccoli.

. Speak, memory: an autobiography revisited. New York: Knopf, 1999.

. Strong Opinions. New York: Vintage International, 1990.

. The Stories of Vladimir Nabokov. New York: Vintage International, 1997. 
Schneider, Graziela - Vladímir Nabókov: as artes da tradução

Paramanov, В. Русская история наконец оправдала себя в литературе, 2000. (A história russa ao final se justificou na la literatura, 2000). Disponível em: <http://www.guelman.ru/slava/kis/paramonov.htm>. (23/09/2008).

Proffer, E. Vladímir Nabokov, uma fotobiografia. São Paulo: Arts Poética, 1994.

SCHEINER, C. L. Bilingualism and biculturalism in self-translation: Samuel Beckett and Vladímir Nabokov as doubled novelists. Ph.D. Dissertation. Chicago: The University of Chicago, 2000.

TANQUEIRO, H. Un traductor privilegiado: el autotraductor. In: Quaderns. Revista de Traducció. n. 3. Barcelona, 1999.

Volkov, S. São Petersburgo: uma história cultural. Trad. de Marco Aarão Reis. São Paulo: Record, 1997. 